\title{
The Research of Common Fault and Processing Methods of 220kV Isolation Switch
}

\author{
Zhu Yuanda, Yi Yongfei, Wang Wei, Jin Xin, Zhao Hui, Zhang Su, Shi Xingcai, \\ Liu Jun, Xu Minghu, Jin Yi
}

The Technical Training Center, Liaoning Electric Power Company Limited, State Grid, China.

fushunpowersupply@163.com

Keywords: Isolation switch of the high voltage alternating current; Rust; Obstructions; Abnormal heat; Porcelain fracture failure

\begin{abstract}
Isolation switch of the high voltage alternating current usually emerge some faults, as the suffered losses of electrical power system is increasing, people will begin to pay attention to the fault problems of isolation switch. Through knowing the basic performance of isolation switch, people give some typical faults and solving problems of isolation switch that often happens in the electrical power system, and improve operating qualities of isolation switch, reduce some faults, improve the stability and security of system.
\end{abstract}

\section{Introduction}

Isolation switch plays an important role in isolating power,separating and closing the low load current,switching operation in the electrical power system. As devices update,Substations where nobody is on duty transform and Substations devices from regular maintenance system to condition maintenance system, the running outside isolation switch appears some problems that are rising greatly in recent years, affect power supply reliability and security of the system directly. In this thesis, it analyzes isolation switch of the alternating current problems, give some solving problems with these problems[1-3].

\section{The isolation switch of the high voltage alternating current in needing technology}

In the electrical network, isolation switch of the high voltage alternating current is used to close and separate the circuit of no load and electrical equipments, its function includes achieving transmission of electricity and security isolation through normal operating current and fault current for the regulation short time credibly in the switching stage, but there are canonical insulation distance and apparent disconnected dots with switch contact in the separating switching stage, and it can make power equipments and power supply security isolation in the load side. The function of isolation switch is relative a little, so its construction is relative simple, there is arc-control device, and it can't connect and disconnect load current. The overwhelming majority of isolation switch of the high voltage alternating current is operating in the open air, expose directly in the atmospheric environment, it is influenced easily by environment and climate, Product design and manufacturing should give full consideration to the factors, to ensure that all can work reliably in rain, wind, ice, snow, dust, cold and hot conditions[4]. 


\section{Isolating switch common faults}

The common fault types of isolating switch in the operation are the following: Porcelain fracture faults, agency problems, conducting loop heating. In the operation of the system, there are more defects and faults in the isolating switch, which involves many aspects of the problem. It can be summed up as the agency problem, include Mechanism of jam, electric not switching, auxiliary switch adjustment that is not in place and so on; The second is the poor contact between the conductive system, it makes the conductive loop heating anomaly, The reason is the switch contact spring faults to bad contact or closing is not in place, such as cracking and loosening, conductive circuit, there is the problem of conducting loop structure of bad; it is the porcelain fracture the most serious faults on the safe operation of the greatest threat[5].

\section{Porcelain fracture faults}

Isolating switch for this failure occurs especially grade flip type in $220 \mathrm{kV}$, and isolating switch is more. Some become a major accident, So great that the influence of post insulator and porcelain fracture problems of rotation over the years have occurred, some are running for many years old products, has just put into operation more than a year before new product.

Insulator rupture and electric porcelain factory product quality are related, also with the overall quality related isolating switch, Insulator cast not equal problem, in addition to cement cementing problems. In addition, quality means lax to run left hidden defects and hidden trouble of insulator is not detected, are assembled into a product, a great threat to the safe operation.

The fracture of porcelain insulator, first from the source to grab, insulator manufacturing factory must be strictly in accordance with the process after careful inspection qualified before the factory. Another variant is to develop timely isolation switch that support insulator ultrasonic flaw detection work and advance prevention. It should increase the no-load operation of machinery number appropriately in a transmission opportunity,, to increase the probability of insulator defects in the blackout operation exposure, but now too much emphasis is on the feasibility of the safe operation of power supply, which brings hidden trouble to the isolation switch.

\section{Agency problem}

Agency problem is the electric can’t divide, close. Isolating switch installation has just put into operation in the factory, electric switching operation is relatively normal. But before long, some one or two years later, there will be various problems, Such as the auxiliary switch problems, including the switch is not in place or bad contacts, resulting in separating and closing switching, But the main electric circuit problems, has no effect on the system in the installation. Processing can be resolved, can't put the defect left to run the scene.

\section{The conductive loop heating}

\section{Disconnecting switch heating causes and characteristics}

A long time in the operation serious environment, and serious static contact finger pressing tight spring characteristic may also be a static contact refers to the unilateral contact, contact clamping spring relaxation deformation, the clamping force is enough to lead the partial contact finger and 
moving contact no contact, the contact finger and moving contact surface is reduced, there is dirty in the dynamic and static contact, and the material is easy to be oxidized and corroded excessive contact after long term operation, the resistance increases and the contact finger has obvious burn pits.

The switch is not in place or scissors clamp structure for the bad clamping. The closing angle deviation, causing the contact surface is not enough, the connection bolt fastening insufficient or excessive cause bolt fracture.

Summer peaks and major holidays load is relatively high fever frequently.

There is a stable high load condition all the year round.

\section{Isolating switch treatment of generating heat}

Early infrared temperature detection, regular infrared temperature detection can timely discover the running status of isolating switch, there is whether the hidden danger of overheating or not.

Maintenance: Isolating switch repairing generally replace the static contact spring clamp and burning the contact finger, remove the static contact oxidation layer, clean contact, wipe conductive adhesive, fix bolt, radical approach is to replace the static contact.

\section{Operational inspection and maintenance of isolating switch}

Perambulatory job is the effective means to discover the equipment defect, the operating personnel patrol work is the main means of infrared temperature measurement, organizing personnel patrol in the special weather, through checking the contacts steaming, the melting snow, also can find out superheat, the main way is improving inspection quality. The equipment maintain, schedule maintenance personnel switch insulator antifouling cleaning and related supporting insulator support for independent isolation, do the ultrasonic flaw detection work, detect timely hidden defect existing equipment. New device put into operation to the vertical pull rod type isolation switch for drilling, to prevent freezing cracking equipment.

\section{Maintenance of isolating switch operation、maintenance suggestions}

When the maintenance schedule, strengthen the $220 \mathrm{kV}$ bus isolation switch maintenance, according to the characteristics of the local environment, it makes the maintenance cycle.

Replacing the spring member contact replacement or the whole static contact should regard the aging degree of shortening in the period.

The main reason of generating heat is the dynamic and static contact resistance contact surface. After repairing, it is whether qualification isolating switch conductive loop resistance measurement or not, and it is the means of quality inspection as a maintenance equipment operation.

Contacting infrared temperature monitoring are the main methods to detect contact generating heat, it is hidden to contact heating equipment and difficult to Patrol, infrared temperature measurement should be further strengthened; The important temperature rising is a general survey, and it found that more than a certain value of the site regularly for temperature measurement; The doubt temperature is larger for large loads and possible heat load point parts of the infrared temperature measurement. 
Infrared temperature measurement data to be archived for future reference, multiple infrared temperatures regularly compare data in order to detect any changing data.

Combined with isolation switch power outage, ultrasonic flaw detection insulator regularly works in accordance with the environmental characteristics, and the magnets are insulator junction point inspection with waterproof glue if necessary.

\section{Conclusion}

We must take the causing accident part of understanding into sufficient attention by isolating switch faults, causing damaging equipment or even blackouts phenomenon. It Should strengthen the process quality management, and flexible processing based on the structure of the device itself; For the routine inspections, it Should grasp the equipment operating conditions, find out the faults and identify the reasons as soon as possible and eliminate hidden dangers, guarantee safe and reliable operation of the power grid. As the progress of science and technology is striding, the isolation switch continuous to improve, performance continues to improve, recommendations based on each unit in order to secure, equipment is improving and replacing, to ensure stability and security of system.

\section{References}

[1] Cao Huashi. The high voltage switch factory and field test. Water Resources and Hydropower press, 1993.

[2] Zhang Jianwen. Electrical equipment fault diagnosis technology. Water Resources and Hydropower press, 2006.

[3] Three live working procedures. China Electric Power Press, 2003.

[4] Chen Tianxiang, Wang Yinzhong. Electrical Test. Beijing: China power press, 2010

[5] Wang Qingkui. Transmission line operation and maintenance. China Electric Power Press, 2003. 